Borgsteede, S.D., Deliens, L., Beentjes, B., Schellevis, F., Stalman, W.A.B., Eijk, J.T.M. van, Wal, G. van der. Symptoms in patients receiving palliative care: a study on patient-physician encounters in general practice. Palliative Medicine: 2007, 21(5), 417-423

\begin{tabular}{|l|l|}
\hline $\begin{array}{l}\text { Postprint } \\
\text { Version }\end{array}$ & 1.0 \\
\hline $\begin{array}{l}\text { Journal website } \\
\text { Pubmed link }\end{array}$ & $\underline{\mathrm{http}: / / \text { pmj.sagepub.com/cgi/reprint/21/5/417 }}$ \\
\hline DOI & $\underline{\mathrm{htt}: / \text { www.ncbi.nlm.nih.gov/pubmed/17901101 }}$ \\
\hline
\end{tabular}

This is a NIVEL certified Post Print, more info at http://www.nivel.eu

\title{
Symptoms in patients receiving palliative care: a study on patient-physician encounters in general practice
}

SANDer D. Borgsteede, Luc Deliens, BarRy BeEnTJes, François SCHELleVis, Wim A.B. STALMAN, JACQUES TH.M. VAN EIJK AND GERRIT VAN DER WAL

Sander D Borgsteede VU University Medical Center, Department of Public and Occupational Health, EMGO Institute, Amsterdam, Luc Deliens VU University Medical Center, Department of Public and Occupational Health, EMGO Institute, Amsterdam, Vrije Universiteit Brussel, End-of-Life Care Research Group, Brussels, Barry Beentjes VU University Medical Center, Department of Public and Occupational Health, EMGO Institute, Amsterdam, François Schellevis Netherlands Institute for Health Services Research (NIVEL), Utrecht, VU University Medical Center, Department of General Practice, EMGO Institute, Amsterdam, Wim AB Stalman VU University Medical Center, Department of General Practice, EMGO Institute, Amsterdam, Jacques ThM Van Eijk University of Maastricht, Department of Health Care Studies/Medical Sociology, Maastricht and Gerrit Van der Wal VU University Medical Center, Department of Public and Occupational Health, EMGO Institute, Amsterdam

Most people with an incurable disease prefer to stay and die at home, cared for by their general practitioner (GP). This paper aims at describing the prevalence of symptoms in patients receiving palliative care at home. Within the framework of a nation wide survey of general practice in the Netherlands, GPs received a questionnaire for all patients who died within the 1-year survey period to determine whether patients received palliative care ( $\left.\mathrm{n}_{-} 2194\right)$. The response rate was $73 \%(n+1608)$, and $38 \%$ of these patients received palliative care until death. Information regarding encounters during the last 3 months of life was derived from the records kept by the GPs. Digestive symptoms (59\%) and pain $(56 \%)$ were the most prevalent. The total number of symptoms per patient was higher in cancer patients (11.99) than in non-cancer patients (7.62). Not reported in previous studies were musculoskeletal symptoms (20\%) and chronic ulcer (18\%). Concluding, this showed that Dutch GPs encounter a diversity and wide range of symptoms in palliative care. To face these complex challenges in patients receiving palliative care at home, GPs have to be trained as well as supported by specialized palliative care consultants. 
Borgsteede, S.D., Deliens, L., Beentjes, B., Schellevis, F., Stalman, W.A.B., Eijk, J.T.M. van, Wal, G. van der. Symptoms in patients receiving palliative care: a study on patient-physician encounters in general practice. Palliative Medicine: 2007, 21(5), 417-423

\section{INTRODUCTION}

Most people with an incurable disease prefer to remain at home surrounded by relatives during the last stage of their life. ${ }^{1-3}$ In the Netherlands, health care is characterized by its strong emphasis on primary care, where the general practitioner (GP) is the central professional in the management and coordination of patient's care. ${ }^{4}$ Almost $60 \%$ of the patients with non-acute illnesses die at home, ${ }^{5}$ and there is a general consensus that palliative care preferably should be provided in the patient's home. ${ }^{6}$ The aging of the population and the growing number of non-acute deaths will increase the need for palliative care. ${ }^{7,8}$ This will also impact on the GP's workload. Symptom management is an important aspect of palliative care, as the World Health Organization (WHO) defines palliative care as: 'an approach that improves the quality of life of patients and their families facing the problems associated with life-threatening illness, through the prevention and relief of suffering by means of early identification and impeccable assessment and treatment of pain and other problems, physical, psychosocial and spiritual'. ${ }^{9}$ Common symptoms in palliative care are pain, dyspnoea, constipation, confusion, nausea and vomiting. ${ }^{10,11}$ Most studies on symptoms were performed in a specific setting, such as a palliative care unit in a hospital or a hospice. Findings from these specialized settings are not always transposable to the community as symptom prevalence differs between settings. ${ }^{12}$ To our knowledge, there is no study in primary care that measures symptoms in a general population receiving palliative care. The underlying disease seems to influence prevalence of symptoms eg, in patients with heart failure who died in a hospice the symptom profile was different from cancer patients. ${ }^{13}$ In cancer patients, symptom prevalence was found to differ with severity of the disease, gender and age. ${ }^{14}$ However, primary care studies have not yet reported on both cancer and noncancer patients within the same study. Detailed information on the prevalence of symptoms in primary care is scarce and fragmented. However, this information is needed to organise future palliative care, to focus education on the most frequent symptoms and to initiate collaboration between relevant disciplines. This study aims to fill this gap by describing the prevalence of symptoms in patients receiving palliative care at home and to analyse differences by gender, age and underlying disease; ie, in cancer and non-cancer patients.

\section{METHODS}

\section{Patients}

The data used in this study were obtained from the second Dutch National Survey of General Practice (DNSGP-2), in which a representative sample of 104 Dutch general practices participated, with a total of 399068 patients involved. ${ }^{15}$ Data from eight practices were excluded; three practices delivered incomplete data; five practices were excluded because the data did not meet the minimum quality criteria. The listed population of the remaining 96 practices was 375899 patients. In these practices 2194 patients died during the survey year (0.6\%). The 1-year period of each practice ended between April 2001 and January 2002. We used two different sources of data in this study. First, the GPs received a post-mortem questionnaire for each patient who died during the survey year. Second, we retrieved information about symptoms from the electronic records in which all patient-GP encounters were collected: each encounter was coded by the GP and we searched for additional symptoms in the free text added by the GPs in the electronic medical record. In the post-mortem questionnaire, GPs reported about the patient's underlying disease, and labelled each patient who received palliative care by indicating whether the patient was or was not provided with palliative care until death. This subjective label by the GP allows all kinds of factors which are related to palliative care in the perception of the labeler to be taken into account. Of the questionnaires sent to GPs, 1771 were returned (81\%), and 1608 were filled in completely ( $73 \%$ valid response rate), and 614 patients $(38 \%)$ were labeled as 'provided with palliative care' by their GPs. As all patients died during the survey year, we 
Borgsteede, S.D., Deliens, L., Beentjes, B., Schellevis, F., Stalman, W.A.B., Eijk, J.T.M. van, Wal, G. van der. Symptoms in patients receiving palliative care: a study on patient-physician encounters in general practice. Palliative Medicine: 2007, 21(5), 417-423

had a varying follow-up: some patients died in the first days of the survey, others died later in the study. To ensure we had an observation period of at least 3 months for each patient, we defined our source population as those who died at least 3 months after the start of the survey year $(\mathrm{n}=1115,69 \%)$. We defined our study population as patients with an observation period of at least 3 months, and who were labelled as palliative care patients by their GP $(\mathrm{n}=429 ; 38 \%)$.

\section{Measurements}

The GPs defined the patient's health problem according to the International Classification of Primary Care (ICPC), a classification following a structure of 17 body systems and seven components from which the first one is dealing with symptoms. The ICPC includes several psychological and social issues as well as request for/talking about euthanasia. 16 The patient's problem could be either a symptom or a disease diagnosis. In addition, the digital free text information about the contact registered in the electronic medical record was available. To retrieve as much information as possible, all free text information was read and scored using a restrictive list of symptoms, combining information from previous studies.12,14,17-21 A symptom was present when it was registered by the GP either as ICPC code, or as free text. The scoring of free text was subject to inter-rater reliability testing. Cohen's kappas were calculated and the inter-rater reliability was good (_ $\left.{ }_{-} 0.79\right) .22$ Symptoms were classified into main categories according to the ICPC chapters based on body systems, in combination with general symptoms, pain and fatigue. Symptoms in body systems with a prevalence larger than $20 \%$ were named according to the specific ICPCchapter, all others were lumped in the category 'other'. Within this classification we made subcategories of symptoms with a prevalence larger than 5\%, all others were categorized as 'other symptoms' under the relevant body system. Data based on routine care delivery during the 1-year study period were extracted from the electronic patient records. For all patients, encounters were analysed during the 3 months before the patient's death. The number of symptoms was expressed as the amount of days on which the specific symptom was registered during a patient-physician encounter. Means for number of symptoms were calculated for the total population. The prevalence of a symptom was defined as the number of patients with at least one encounter about a specific symptom during the last 3 months of life (numerator) divided by the total number of patients (denominator). Furthermore, patient characteristics were extracted from the patient registration data of the practice administration. In the post-mortem questionnaire, we asked about existing underlying diseases using a limitative list.

\section{Statistical analysis}

Characteristics of the palliative care population were analysed. Descriptive statistics were used for prevalence of symptoms in palliative care patients and the mean number of symptoms per patient. Differences in prevalence of symptoms between subpopulations were calculated for the characteristics sex, age and underlying disease, ie, cancer versus noncancer patients, and tested using $\chi$-square test $(\alpha=0.05)$. The mean number of symptoms was compared between sexes and between cancer and non-cancer patients with Student's ttests. During the last 12 weeks of life, we longitudinally investigated the prevalences of symptoms in six 2-week periods until death.

[TABLE 1] 
Borgsteede, S.D., Deliens, L., Beentjes, B., Schellevis, F., Stalman, W.A.B., Eijk, J.T.M. van, Wal, G. van der. Symptoms in patients receiving palliative care: a study on patient-physician encounters in general practice. Palliative Medicine: 2007, 21(5), 417-423

\section{RESULTS}

\section{Symptoms in patient-physician encounters}

In total, 429 patients with an observation period of at least 3 months received palliative care by their GP until death. Characteristics of the study population are presented in Table 1. In patient-physician encounters during the last 3 months of life, $92 \%$ of the patients had at least one symptom, and the mean number of symptoms registered by the GP was 10.0 (Table 2). Digestive symptoms were prevalent in $255(59 \%)$ of the patients. The total number of digestive symptoms was 887 , resulting in a mean number of 2.07 per patient in the last 3 months of life. Within the digestive symptoms, most patients had problems with eating or drinking $(29 \%)$, and nausea or vomiting $(25 \%)$. The prevalence of pain in palliative care patients was $56 \%$. Within psychological symptoms, restlessness $(25 \%)$, sleeping problems $(17 \%)$ and anxiety $(13 \%)$ were the most prevalent symptoms. Within the category other, musculoskeletal symptoms (20\%), chronic ulcer (18\%) and requests for/talking about euthanasia (14\%) were most common. There was a mean number of 10.0 symptoms in the last 3 months of life, and the corresponding range was wide $(0-68$, median $=8)$.

\section{Symptoms by sex, age and underlying disease}

There was no difference in the prevalence of symptoms between males and females receiving palliative care at home. The mean number of respiratory symptoms and fatigue was higher in males than in females, while the mean number of other symptoms was higher in females ( $\mathrm{P}<0.05$, data not shown). There was a lower prevalence of digestive symptoms, pain and psychological symptoms by patients in older age groups (Table 3 ). The prevalence of urogenital symptoms was higher in older age groups. The mean number of symptoms was significantly higher in patients under 70 (11.25) than in patients over 90 (9.0). Cancer patients had more pain, digestive symptoms, psychological symptoms and fatigue than noncancer patients (Table 4). Compared to cancer patients, non-cancer patients had more urogenital symptoms. The mean number of all symptoms was 11.99 for cancer patients and 7.62 for noncancer patients. Table 5 shows symptom prevalences for cancer and non-cancer patients by age-group. In cancer patients, the prevalence of psychological symptoms was lower in older age-groups. This trend was not significant for pain. In cancer patients, prevalence of fatigue and urogenital symptoms was higher in older age-groups. In noncancer patients the prevalence of fatigue and other symptoms was higher in older agegroups.

\section{Symptoms during the last 12 weeks of life}

Figure 1 shows the prevalence of symptoms in different body systems in the last 3 months of life. With the exception of circulatory and urogenital symptoms, all symptoms showed a small increase in prevalence in the period 3-4 weeks before death and a substantial increase in prevalence in the last 2 weeks before death. In total, $36 \%$ of all symptoms within the 3 month period occurred in the last 2 weeks of life and $61 \%$ of all patients had at least one symptom during these last 2 weeks.

\section{[FIGURE 1]}

\section{[TABLE 2]}

\section{DISCUSSION}

In the patients who died at home and who received palliative care until death by their GP, digestive symptoms (59\%), pain (56\%) and psychosocial symptoms (45\%) were most prevalent. Also, musculoskeletal symptoms (20\%), chronic ulcer (18\%) and request for/talking about euthanasia (14\%) were prevalent in patient-physician encounters. The mean 
Borgsteede, S.D., Deliens, L., Beentjes, B., Schellevis, F., Stalman, W.A.B., Eijk, J.T.M. van, Wal, G. van der. Symptoms in patients receiving palliative care: a study on patient-physician encounters in general practice. Palliative Medicine: 2007, 21(5), 417-423

number of encounters about any symptom was higher in cancer patients (11.99) than in noncancer patients (7.62). Also, in younger patients and in cancer patients the prevalence of digestive symptoms, pain and psychological symptoms was higher than in the elderly and the non-cancer patients. Most symptoms (36\%) were concentrated in the last 2 weeks of life. This paper was embedded in the DNSGP-2, which has generated solid data due to its quality and size. The total response rate of $73 \%$ for the post-mortem questionnaire was high compared to mean response rates of $61 \%$ reported in studies carried out in general practice, and a trend of decreasing rates of response to mail questionnaires.23 As most studies in palliative care are limited to cancer patients, 24 a further strength is that this study is population based, and that we included both cancer and non-cancer patients. The limitations of this paper are that no information was obtained about the severity of symptoms, and we were unable to measure whether the management of the symptoms resulted in improvement of symptom control. Besides, we measured symptoms that were prevalent in encounters according to physicians. In primary care, agreement between patients and GPs assessment on the prevalence of physical symptoms is acceptable, 17 but it is likely that GPs did not register all symptoms affecting these patients. Hence, the numbers of symptoms per patient is probably an underestimation. Also the GPs might not have registered the less serious symptoms, so the symptoms registered in the electronic medical records represent the more important symptoms according to the GPs.

\section{[TABLE 3]}

The most important result is that prevalence of symptoms differs by age group and underlying disease. Overall, prevalence of symptoms is higher for younger patients and for cancer patients. For cancer patients, prevalence of pain and psychological problems decreases with age, while prevalence of fatigue and urogenital symptoms increases with age. Because of the different nature of the disease, the frequency of symptoms in cancer patients might be higher than in noncancer patients. On the other hand, a study that compared symptoms in lung cancer patients with chronic obstructive pulmonary disease patients, found a similar symptom burden in both patient populations. ${ }^{25}$ As we have not measured the needs, the severity of symptoms and the need for encounters we cannot say whether the received care met the needs of the patients. Other studies have found that prevalence of symptoms was higher in younger patients. ${ }^{14,26}$ Our study confirms this general finding in both cancer and non-cancer patients, although some symptoms show a higher prevalence in older age groups eg, fatigue and urogenital symptoms. Possibly, younger patients have better access to palliative care, ${ }^{27}$ or GPs are more sensitive to their younger end-of-life patients. Another explanation is that younger patients and cancer patients have more encounters about symptoms because they can stay at home with a more severe disease because they have a reliable support system, or that older patients have a more mitigated disease trajectory. ${ }^{28}$

\section{[TABLE 4]}

\section{[TABLE 5]}

Within our paper we found a wide range in total number of symptoms in patients, including $8 \%$ of all patients without any encounter about symptoms. This proportion is similar with proportions found in other studies.18,19 The wide range of symptom prevalence across studies, and between patients within a study, makes comparisons between studies difficult. Our paper is based on symptoms registered during encounters, where most other studies measured symptoms that were prevalent using a list of possible symptoms, eg, the Palliative Care Outcome Scale or the Edmonton Symptom Assessment System.29,30 GPs encounter a 
Borgsteede, S.D., Deliens, L., Beentjes, B., Schellevis, F., Stalman, W.A.B., Eijk, J.T.M. van, Wal, G. van der. Symptoms in patients receiving palliative care: a study on patient-physician encounters in general practice. Palliative Medicine: 2007, 21(5), 417-423

wide range of problems in patients receiving palliative care. Some of these are specific to the palliative care population, while others are typical in a common population of the elderly, such as musculoskeletal symptoms and chronic ulcer that have not been reported in previous studies. Compared to specialists, GPs may be less focused on symptoms that are often associated with palliative care such as pain and digestive symptoms, and more sensitive to the diversity of the symptoms they encounter. According to the European Association of Palliative Care ethics task force, the position of communication about euthanasia is more complex. They state that 'requests for euthanasia require respect, careful attention, together with open and sensitive communication', communication about euthanasia can be regarded as part of the palliative care.31 The relatively high prevalence of communication about euthanasia is likely related to legislation in the Netherlands.32 Future studies should explicitly explore the prevalence of, and the need for communication on end-oflife issues in patients receiving palliative care. We have shown that the number of symptoms is the highest for cancer patients, and that it is concentrated in the last 2 weeks of life. This requires a peak performance from GPs, especially when they care for more than one palliative care patient at a time. To support GPs so that they can provide good palliative care, continuous education33 and the possibility to consult palliative care experts are essential to safeguard quality in palliative care at home.34 In primary care, future developments such as the restriction of time for home visits, more part-time jobs and cooperatives responsible for care after officehours, 4 may threaten the core values of palliative care, such as the availability of the GP for home and after-hours visits. 35 Palliative care faces the challenge of combining these future developments with the necessity for GPs to be available to give palliative care to more patients needing symptom control.

\section{REFERENCES}

1 Charlton RC. Attitudes towards care of the dying: a questionnaire survey of general practice attenders. Fam Pract 1991; 8: 356-59.

2 Dunlop RJ, Davies RJ, Fermont D. Preferred versus actual place of death; a hospital palliative care support team study. Palliat Med 1989; 3: 197-201.

3 Townsend J, Frank AO, Fermont D, et al. Terminal cancer care and patients' preference for place of death: a prospective study. Br Med J 1990; 301: 415-17.

4 Health Council of the Netherlands. European primary care. 2004/20E. 16-12-2004. The Hague, Health Council of the Netherlands.

5 Francke A, Willems D. Palliatieve zorg vandaag en morgen. [Palliative care today and tomorrow]. Elsevier gezondheidszorg, 2000.

6 Janssens RJ, Ten Have HA. The concept of palliative care in The Netherlands. Palliat Med 2001; 15: 481-86.

7 McLaren G, Preston C, Grant B. Evidence based palliative care. General palliative care should be evaluated. Br Med J

1999; 319: 1573.

8 Cartwright A. Changes in life and care in the year before death 1969-1987. J Public Health Med 1991; 13: 81-87.

9 WHO. National cancer control programmes: policies and managerial guidelines.World Health Organization, 2002.

$10 \mathrm{Ng} \mathrm{K}$, Von Gunten CF. Symptoms and attitudes of 100 consecutive patients admitted to an acute hospice/palliative care unit. J Pain Symptom Manage 2000; 16: 307-16.

11 Seamark DA, Lawrence C, Gilbert J. Characteristics of referrals to an in patient hospice and a survey of general practitioner perceptions of palliative care. J R Soc Med 1996; 89: 79-84.

12 Potter J, Hami F, Bryan T, Quigley C. Symptoms in 400 patients referred to palliative care services: prevalence and patterns. Palliat Med 2003; 17: 310-14.

13 Zambroski CH, Moser DK, Roser LP, Heo S, Chung ML. Patients with heart failure who die in hospice. Am Heart $\mathrm{J}$

2005; 149: 558-64. 
Borgsteede, S.D., Deliens, L., Beentjes, B., Schellevis, F., Stalman, W.A.B., Eijk, J.T.M. van, Wal, G. van der. Symptoms in patients receiving palliative care: a study on patient-physician encounters in general practice. Palliative Medicine: 2007, 21(5), 417-423

14 Walsh D, Donnelly S, Rybicki L. The symptoms of advanced cancer: relationship to age, gender, and performance status in 1,000 patients. Support Care Cancer 2000; 8: 175-79. 15 Westert GP, Schellevis FG, de Bakker DH, Groenewegen PP, Bensing JM, van der Zee J. Monitoring health inequalities through general practice: the Second Dutch National Survey of General Practice. Eur J Public Health 2005; 15: 59-65.

16 Lamberts H,Woods M, Hofmans-Okkes I eds. The international classification of primary care in the European community. Oxford University Press, 1993. 17 Ewing G, Rogers M, Barclay S, et al. Palliative care in primary care: a study to determine whether patients and professionals agree on symptoms. Br J Gen Pract 2006; 56: 27-34.

18 Grond S, Zech D, Diefenbach C, Bischoff A. Prevalence and pattern of symptoms in patients with cancer pain: a prospective evaluation of 1635 cancer patients referred to a pain clinic. J Pain Symptom Manage 1994; 9: 372-82.

19 Schuit KW, Sleijfer DT, Meijler WJ, et al. Symptoms and functional status of patients with disseminated cancer visiting outpatient departments. J Pain Symptom Manage 1998; 16: 290-97.

20 Conill C, Verger E, Henriquez I, et al. Symptom prevalence in the last week of life. J Pain Symptom Manage 1997; 14: 328-31.

21 Jenkins CA, Schultz M, Hanson J, Bruera E. Demographic, symptom, and medication profiles of cancer patients seen by a palliative care consult team in a tertiary referral hospital. J

Pain Symptom Manage 2000; 19: 174-84.

22 Altman DG. Practical statistics for medical research.

Chapman \& Hall, 1991.

23 Sibbald B, Addington-Hall J, Brenneman D, Freeling P. Telephone versus postal surveys of general practitioners: methodological considerations. Br J Gen Pract 1994; 44: 297-300.

24 George LK. Research design in end-of-life research: state of science. Gerontologist 2002; 42: 86-98.

25 Gore JM, Brophy CJ, Greenstone MA. How well do we care for patients with end stage chronic obstructive pulmonary disease (COPD)? A comparison of palliative care and quality of life in COPD and lung cancer. Thorax 2000; 55: 1000-1006.

26 Morita T, Tsunoda J, Inoue S, Chihara S. Contributing factors to physical symptoms in terminally-ill cancer patients. J Pain Symptom Manage 1999; 18: 338-46.

27 Grande GE, Farquhar MC, Barclay SI, Todd CJ. The influence of patient and carer age in access to palliative care services. Age Ageing 2006; 35: 267-73.

28 Walsh D, Regan J. Terminal care in the home-the general practice perspective. Ir Med J 2001; 94: 9-11.

29 Hearn J, Higginson IJ. Development and validation of a core outcome measure for palliative care: the palliative care outcome scale. Qual Health Care 1999; 8: 219-27.

30 Bruera E, Kuehn N, Miller MJ, Selmser P, Macmillan K. The Edmonton Symptom Assessment System (ESAS): a simple method for the assessment of palliative care patients. J Palliat Care 2000; 7: 6-9.

31 Materstvedt LJ, Clark D, Ellershaw J, et al. Euthanasia and physician-assisted suicide: a view from an EAPC Ethics Task Force. Palliat Med 2003; 17: 97-101.

32 Norwood, F. Euthanasia talk. Euthanasia discourse, general practice and end-of-life care in the Netherlands (dissertation). University of California, San Francisco, CA, USA, 2005.

33 Meijler WJ, Van Heest F, Otter R, Sleijfer DT. Educational needs of general practitioners in palliative care: outcome of a focus group study. J Cancer Educ 2005; 20: 28-33.

34 Kuin A, Courtens AM, Deliens L, et al. Palliative care consultation in The Netherlands: a nationwide evaluation study. J Pain Symptom Manage 2004; 27: 53-60.

35 Borgsteede SD, Graafland-Riedstra C, Deliens L, Francke AL, van Eijk JT, Willems DL. Good end-of-life care according to patients and their GPs. Br J Gen Pract 2006; 56: 20-26. 
Borgsteede, S.D., Deliens, L., Beentjes, B., Schellevis, F., Stalman, W.A.B., Eijk, J.T.M. van, Wal, G. van der. Symptoms in patients receiving palliative care: a study on patient-physician encounters in general practice. Palliative Medicine: 2007, 21(5), 417-423

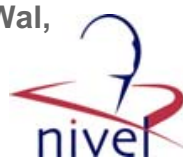

\section{TABLES AND FIGURE}

Table 1 Characteristics of the study population of patients who received palliative care until death in general practice in the Netherlands, with an observation period of at least 3 months $(n=429)$

\begin{tabular}{ll}
\hline & $\%(n-429)$ \\
\hline $\begin{array}{l}\text { Sex } \\
\text { Male }\end{array}$ & 47 \\
Female & 53 \\
Age (years) & \\
$<70$ & 28 \\
$70-79$ & 24 \\
$80-89$ & 31 \\
$\geq 90$ & 16 \\
Mean (SD) & $76.8(13.9)$ \\
Underlying disease* & \\
Cancer & 56 \\
Non-cancer & 44 \\
$\quad$ Heart failure & 11 \\
COFD & 3.1 \\
Other disease & 25 \\
Multiple non-cancer disesses & 4.5 \\
\hline
\end{tabular}

* Number of missing values for underlying disease was 3.

COPD, chronic obstructive pulmonary disease.

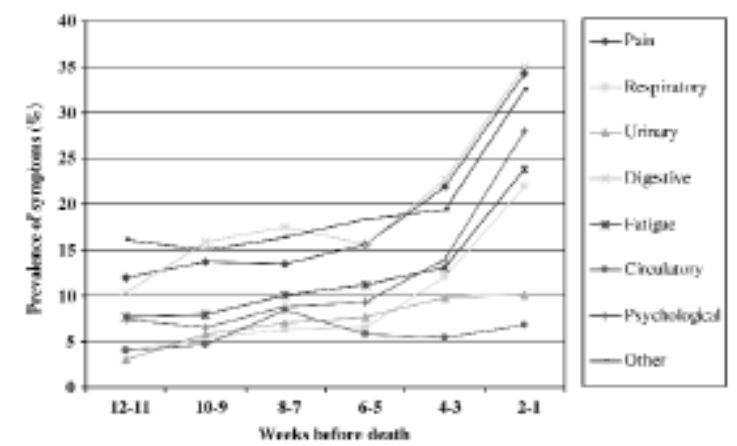

Figure 1 Prevalence of symptoms in patients receiving palliative care in six 2 week periods before death. 
Borgsteede, S.D., Deliens, L., Beentjes, B., Schellevis, F., Stalman, W.A.B., Eijk, J.T.M. van, Wal, G. van der. Symptoms in patients receiving palliative care: a study on patient-physician encounters in general practice. Palliative Medicine: 2007, 21(5), 417-423

Table 2 Prevalence and number of symptoms in patients receiving pelliative care during the last 3 months of life $(n=429)$

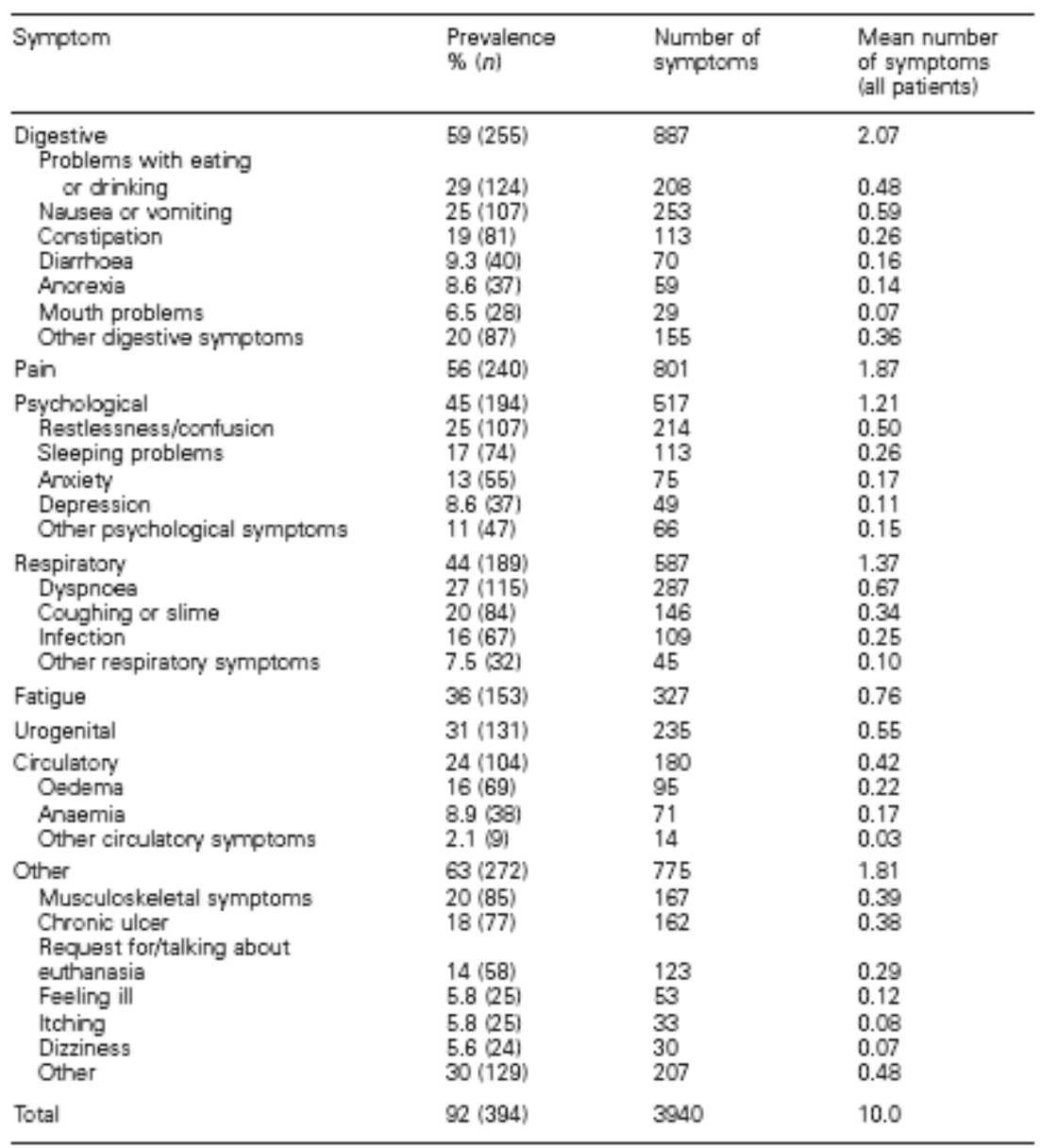


Borgsteede, S.D., Deliens, L., Beentjes, B., Schellevis, F., Stalman, W.A.B., Eijk, J.T.M. van, Wal, G. van der. Symptoms in patients receiving palliative care: a study on patient-physician encounters in general practice. Palliative Medicine: 2007, 21(5), 417-423

Table 3 Prevalence and the mean number of symptoms in patients receiving palliative care during the last 3 months of life by age $(n=429)$

\begin{tabular}{|c|c|c|c|c|c|c|c|c|c|}
\hline & \multicolumn{2}{|c|}{$\begin{array}{l}<70 \text { years } \\
\langle n-120\rangle\end{array}$} & \multicolumn{2}{|c|}{$\begin{array}{c}70-79 \text { years } \\
(n-103)\end{array}$} & \multicolumn{2}{|c|}{$\begin{array}{c}80-89 \text { years } \\
(n-136)\end{array}$} & \multicolumn{2}{|c|}{$\begin{array}{l}\geq 90 \text { yesrs } \\
(n-70)\end{array}$} & \multirow[b]{2}{*}{$\begin{array}{l}\mathrm{P}(x- \\
\text { square })^{*}\end{array}$} \\
\hline & $\begin{array}{l}\text { Prevalence } \\
\text { (\%) }\end{array}$ & $\begin{array}{l}\text { Mean } \\
\text { number } \\
\text { symptoms }\end{array}$ & $\begin{array}{l}\text { Prevalence } \\
(\%)\end{array}$ & $\begin{array}{l}\text { Mean } \\
\text { number } \\
\text { symptoms }\end{array}$ & $\begin{array}{l}\text { Prevalence } \\
(\%)\end{array}$ & $\begin{array}{l}\text { Mesn } \\
\text { number of } \\
\text { symptoms }\end{array}$ & $\begin{array}{l}\text { Prevalence } \\
(\%)\end{array}$ & $\begin{array}{l}\text { Mesn } \\
\text { number of } \\
\text { symptoms }\end{array}$ & \\
\hline $\begin{array}{l}\text { Digestive } \\
\text { Pain } \\
\text { Psychological } \\
\text { Respiratory } \\
\text { Fatigue } \\
\text { Urogenital } \\
\text { Crrculatory } \\
\text { Other }\end{array}$ & $\begin{array}{l}67 \\
66 \\
68 \\
47 \\
36 \\
20 \\
21 \\
62\end{array}$ & $\begin{array}{l}2.78 \\
2.26 \\
1.41 \\
1.71 \\
0.77 \\
0.36 \\
0.33 \\
1.64\end{array}$ & $\begin{array}{l}66 \\
62 \\
47 \\
47 \\
36 \\
30 \\
31 \\
60\end{array}$ & $\begin{array}{l}2.02 \\
2.22 \\
1.26 \\
1.46 \\
0.90 \\
0.46 \\
0.52 \\
1.70\end{array}$ & $\begin{array}{l}52 \\
49 \\
38 \\
39 \\
35 \\
36 \\
23 \\
65\end{array}$ & $\begin{array}{l}1.49 \\
1.60 \\
1.07 \\
1.15 \\
0.71 \\
0.73 \\
0.41 \\
1.99\end{array}$ & $\begin{array}{l}51 \\
44 \\
34 \\
46 \\
36 \\
39 \\
23 \\
67\end{array}$ & $\begin{array}{l}2.04 \\
1.19 \\
1.04 \\
1.09 \\
0.66 \\
0.66 \\
0.42 \\
1.90\end{array}$ & $\begin{array}{l}0.006 \\
0.000 \\
0.000 \\
0.478 \\
0.952 \\
0.002 \\
0.985 \\
0.339\end{array}$ \\
\hline $\begin{array}{l}\text { At least one } \\
\text { symptom }\end{array}$ & 94 & 11.25 & 94 & 10.54 & 90 & 9.14 & 94 & 9.00 & 0.424 \\
\hline
\end{tabular}

" $x$-square for trend. Linear-by-linear association.

Table 4 Prevalence and the mean number of symptoms in patients receiving palliative care during the last 3 months of life: cancer versus non-cancer patients $(n=426$ )*

\begin{tabular}{|c|c|c|c|c|c|c|}
\hline & \multicolumn{2}{|c|}{ Cancer $n-238$} & \multicolumn{2}{|c|}{ Non-cancer $n-188$} & \multirow[b]{2}{*}{$\mathrm{P}$ ( $\mathrm{x}$-square) } & \multirow[b]{2}{*}{ P (Student's $t$ ) } \\
\hline & $\begin{array}{l}\text { Prevalence } \\
(\%)\end{array}$ & $\begin{array}{l}\text { Mean number } \\
\text { of symptoms }\end{array}$ & $\begin{array}{l}\text { Prevalence } \\
(\%)\end{array}$ & $\begin{array}{l}\text { Mean number } \\
\text { of symptoms }\end{array}$ & & \\
\hline $\begin{array}{l}\text { Digestive } \\
\text { Pain } \\
\text { Psychological } \\
\text { Respiratory } \\
\text { Fatigue } \\
\text { Urogenital } \\
\text { Circulatory } \\
\text { Other }\end{array}$ & $\begin{array}{l}72 \\
65 \\
53 \\
42 \\
45 \\
25 \\
25 \\
64\end{array}$ & $\begin{array}{l}2.75 \\
2.62 \\
1.45 \\
1.48 \\
1.00 \\
0.44 \\
0.42 \\
1.82\end{array}$ & $\begin{array}{l}43 \\
45 \\
36 \\
45 \\
24 \\
37 \\
23 \\
63\end{array}$ & $\begin{array}{l}1.19 \\
0.93 \\
0.91 \\
1.22 \\
0.46 \\
0.69 \\
0.41 \\
1.80\end{array}$ & $\begin{array}{l}0.000 \\
0.000 \\
0.000 \\
0.623 \\
0.000 \\
0.008 \\
0.820 \\
0.840\end{array}$ & $\begin{array}{l}0.000 \\
0.000 \\
0.005 \\
0.268 \\
0.000 \\
0.017 \\
0.872 \\
0.959\end{array}$ \\
\hline $\begin{array}{l}\text { At least one } \\
\text { symptom }\end{array}$ & 94 & 11.99 & 91 & 7.62 & 0.454 & 0.000 \\
\hline
\end{tabular}

* Number of missing values for underlying disease was 3. 
Table 5 Prevalence of symptoms in petients receiving palliative care during the last 3 months of life, by age and underlying disease $(n=426)$ *

\begin{tabular}{|c|c|c|c|c|c|c|c|c|c|c|}
\hline & \multicolumn{2}{|c|}{$<70$ years $n-120$} & \multicolumn{2}{|c|}{$70-79$ years $n-102$} & \multicolumn{2}{|c|}{$80-89$ years $n-135$} & \multicolumn{2}{|c|}{$\geq 90$ yeas $n-69$} & \multirow{2}{*}{$\frac{\text { Canoer }}{\mathrm{P}^{\dagger}\left(\gamma_{\text {square }}\right.}$} & \multirow{2}{*}{$\begin{array}{l}\text { Non-cancer } \\
\mathrm{P}(x \text {-square })\end{array}$} \\
\hline & $\begin{array}{l}\text { Canos (\%) } \\
n=100\end{array}$ & $\begin{array}{l}\text { Noricanoer } \\
(\%) n=11\end{array}$ & $\begin{array}{l}\text { Cancer (\$) } \\
n=68\end{array}$ & $\begin{array}{l}\text { Norncanor } \\
(\%) n=34\end{array}$ & $\begin{array}{l}\text { Canoser (\%) } \\
n=48\end{array}$ & $\begin{array}{l}\text { Noncancer } \\
(\%) n=87\end{array}$ & $\begin{array}{l}\text { Carner (\%) } \\
n=13\end{array}$ & $\begin{array}{l}\text { Noncancer } \\
(\%) n=56\end{array}$ & & \\
\hline $\begin{array}{l}\text { Digestive } \\
\text { Pain } \\
\text { Psychobgical } \\
\text { Respiratory } \\
\text { Fatigue } \\
\text { Urogenital } \\
\text { Circultory } \\
\text { Other }\end{array}$ & $\begin{array}{l}69 \\
67 \\
61 \\
47 \\
39 \\
19 \\
21 \\
64\end{array}$ & $\begin{array}{c}46 \\
55 \\
36 \\
46 \\
9 \\
27 \\
18 \\
36\end{array}$ & $\begin{array}{l}77 \\
68 \\
54 \\
46 \\
47 \\
28 \\
31 \\
63\end{array}$ & $\begin{array}{l}44 \\
50 \\
32 \\
47 \\
15 \\
35 \\
29 \\
53\end{array}$ & $\begin{array}{l}73 \\
58 \\
40 \\
29 \\
52 \\
29 \\
23 \\
65\end{array}$ & $\begin{array}{l}41 \\
44 \\
38 \\
44 \\
25 \\
39 \\
23 \\
66\end{array}$ & $\begin{array}{l}77 \\
54 \\
39 \\
39 \\
62 \\
46 \\
31 \\
62\end{array}$ & $\begin{array}{l}45 \\
43 \\
34 \\
46 \\
30 \\
37 \\
21 \\
70\end{array}$ & $\begin{array}{l}0.409 \\
0.222 \\
0.010 \\
0.086 \\
0.038 \\
0.026 \\
0.449 \\
0.925\end{array}$ & $\begin{array}{l}1.000 \\
0.387 \\
1.000 \\
1.000 \\
0.043 \\
0.593 \\
0.684 \\
0.021\end{array}$ \\
\hline $\begin{array}{l}\text { At last one } \\
\text { symptom }\end{array}$ & 94 & 100 & 96 & 91 & 90 & 90 & 100 & 93 & 0.953 & 0.758 \\
\hline
\end{tabular}

Num ber of missing values for underlying disease was 3.

${ }^{\dagger} X$-square for trend. Lin

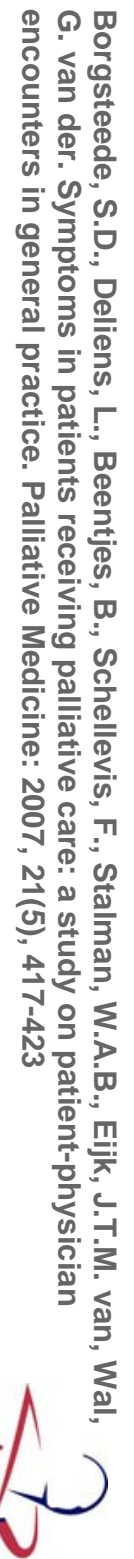

